\title{
Establishment of Sexual Dimorphism in North Indian Population by Odontometric Study of Permanent Maxillary Canine
}

Shalini Gupta ${ }^{1 *}$, Akhilesh Chandra ${ }^{2}$, Om Prakash Gupta ${ }^{3}$, Yogendra Verma ${ }^{1}$ and Saurabh Srivastava ${ }^{1}$

${ }^{1}$ Department of Oral Pathology, King George's Medical University, Lucknow, India

${ }^{2}$ Department of Oral Pathology, Institute of Dental Sciences, BHU, Vanarasi, UP, India

${ }^{3}$ Department of General Surgery, Carrier Institute of Medical Sciences, Lucknow, India

\begin{abstract}
Aim: To investigate whether sexual dimorphism can be established by odontometric study of permanent maxillary canine teeth as well as inter-canine width in north Indian population.

Study design: The study was carried out at department of oral and maxillofacial pathology, King George's Medical University, Lucknow, India on students and patients reporting at OPD. Out of total 180 subjects examined 90 subjects were female and 90 were male. Impressions of the upper arch were made using alginate and casts poured in dental stone. The mesiodistal diameter of the crown of permanent maxillary canine both on right and left sides and inter-canine width were measured. From these measurements, maxillary canine index was calculated. The percentage of sexual dimorphism was assessed for all the parameters.
\end{abstract}

Results: In the present study, the mesiodistal diameter of maxillary canine for both right $(p=0.001)$ and left side $(p=0.005)$ was significantly higher among male subjects than females, Similar observation was found for inter-canine width too $(p=0.0001)$. However, the maxillary canine index for right and left was almost similar $(p>0.05)$ for both male and female subjects.

The sexual dimorphism in right and left mesiodistal diameters of maxillary canine was $4.2 \%$ and $3.6 \%$ respectively. For, inter-canine width it was maximum i.e. $13.7 \%$. However, sexual dimorphism in right and left canine index showed negative values i.e. $-2.1 \%$ and $-0.9 \%$ respectively.

Conclusion: There was sexual dimorphism in mesiodistal diameter and inter-canine width of permanent maxillary canine teeth. Sexual dimorphism was more on right permanent maxillary canine teeth than left permanent maxillary canine.

Keywords: Forensic odontology; Maxillary canine teeth; Odontometric study; Sex determination; Sexual dimorphism; Odontometry

\section{Introduction}

Sex determination is an important step in determining the biological profile of unidentified human remains, since a correct result would automatically exclude about half the population in search operations [1]. "Sexual Dimorphism" refers to those differences in size, stature and appearance between male and female that can be applied to dental identification [2].

Sex differentiation in forensic investigation utilises craniofacial morphology, tooth dimensions and DNA analysis [3,4]. It has been suggested that odontometrics plays an important role in determination of sex in young individuals where secondary sexual characteristics have not developed. In addition, the resistance of teeth to postmortem insults render them as a valuable tool in forensic investigation [4].

According to Boaz et al. (2009) teeth are known to have sexual dimorphism [5]. Sex determination using dental features is mainly based upon the comparison of tooth dimensions in males and females [6]. The mesiodistal diameter of mandibular and maxillary canines provides evidence of sex determination due to dimorphism [7]. Bosset and Marks and Krogh [8,9] stated that the study of the canine teeth offers certain advantages. They are the least frequently extracted teeth and being less affected by periodontal disease. Canine teeth have also been reported to survive in air and hurricane disasters [10].

Few studies on dental sex dimorphism exist for South-Asian populations which includes the 'canine index' formulated by Rao et al. in Indians $[11,12]$. The objectives of the present study were to investigate whether dimorphism of permanent maxillary canine teeth as well as inter-canine width play a role in establishing sex identity in North Indian Population.

\section{Materials and Methods}

Present study was carried out at Department of Oral and Maxillofacial Pathology, King George's Medical University, Lucknow, India after the approval from the ethical committee of the institute.

The sample for the study comprised of 180 dental casts that belonged to 90 females and 90 males, all students and patients reporting at OPD at the King George's Medical University, Lucknow, UP.

Following verbal consent, impressions of the upper arch were made using alginate material and casts poured in dental stone. The study included young adults with an average age of 23.13 and 20.72 years

${ }^{*}$ Corresponding author: Shalini Gupta, Department of Oral Pathology, King George's Medical University, Lucknow, UP, India, Tel: +91-9453556510; E-mail: sgmds2002@yahoo.co.in

Received October 30, 2013; Accepted February 18, 2014; Published February 28, 2014

Citation: Gupta S, Chandra A, Gupta OP, Verma Y, Srivastava S (2014) Establishment of Sexual Dimorphism in North Indian Population by Odontometric Study of Permanent Maxillary Canine. J Forensic Res 5: 224 doi:10.4172/2157 7145.1000224

Copyright: ( 2014 Gupta S, et al. This is an open-access article distributed under the terms of the Creative Commons Attribution License, which permits unrestricted use, distribution, and reproduction in any medium, provided the original author and source are credited. 


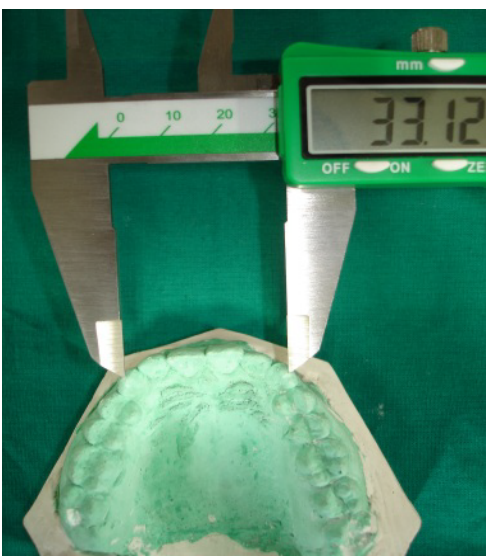

Figure 1: Photograph showing the measurement of inter-canine width of permanent maxillary right to left canine.

\begin{tabular}{|c|c|c|c|c|c|c|}
\hline \multirow{2}{*}{ Parameters } & \multicolumn{3}{|c|}{ Male (n=90) } & \multicolumn{2}{|c|}{ Female (n=90) } \\
\cline { 2 - 6 } p-value & Mean \pm sd & Min.-Max. & CV (\%) & Mean \pm sd & $18-24$ \\
\hline Age in years & $23.13 \pm 2.85$ & $18-30$ & 2.63 & $20.72 \pm 1.25$ & 3.47 \\
\hline $\begin{array}{c}\text { Right mesiodistal diameter of } \\
\text { maxillary canine (in mm.) }\end{array}$ & $8.13 \pm 0.67$ & $6.00-10.00$ & 8.28 & $7.80 \pm 0.70$ & $6.00-9.70$ \\
\hline $\begin{array}{c}\text { Left mesiodistal diameter of } \\
\text { maxillary canine (in mm.) }\end{array}$ & $8.07 \pm 0.71$ & $6.00-10.00$ & 8.78 & $7.79 \pm 0.60$ & $6.00-9.00$ \\
\hline Inter canine width & $41.00 \pm 3.10$ & $35.50-49.50$ & 7.55 & $36.05 \pm 2.32$ & $31.50-42.00$ \\
\hline
\end{tabular}

Table 1: Descriptive statistics for the measurements recorded.

for male and females respectively and one would have assumed that the dentitions were relatively intact and unaltered by the vagaries of pathology and physiologic wear.

Method for the cast preparation are first impression of upper arch were made using alginate material and then cast poured in dental stone.

A few teeth in many of the casts did, however, present restorations, caries, excessive wear or casting defects. If such obstructions impeded tooth measurements, they were not included in the analysis. Mesiodistal diameter (MD) and inter-canine width (ICW) measurements of permanent maxillary canine were obtained using a sliding digital calliper with calibration of $0.01 \mathrm{~mm}$. The measurements were performed by one person and all values were rounded to two decimal places (Figure 1).

\section{Mesiodistal Measurement (MD)}

The greatest mesiodistal dimension between the approximate surfaces of the crown was measured with the calliper beaks placed occlusally along the long axis of the tooth. In case of tooth rotation or malposition, the measurements were taken between points on the approximate surfaces of the crown where it was considered that contact with adjacent teeth would have normally occurred.

\section{Inter-Canine Width (ICW)}

The other measurement consisted of the distance between the tips of the two maxillary canines in a straight line. To measure the distance, each of the calliper beak was kept over the centre of the tip of canine tooth of each side.

\section{Maxillary Canine Index (MCI)}

Maxillry Canine Index=Mesiodistal crown width of maxillary canine/Maxillary inter-canine width

\section{Sexual Dimorphism (SD)}

Sexual dimorphism was calculated using formula given by Garn and Lewis12 as follows:

Sexual Dimorphism $=[\mathrm{Xm} / \mathrm{Xf}]-1 \times 100$

Where: $\mathrm{Xm}=$ Mean value for males; $\mathrm{Xf}=$ Mean value for females

\section{Statistics and Results}

The mean age for males was $23.13( \pm 2.85)$ years and $20.72( \pm 1.25)$ years for females (Table 1). MD of maxillary canine for both right (Male-8.13 $\pm 0.67 \mathrm{~mm}$, Female-7.80 $\pm 0.70 \mathrm{~mm}$ ) and left (Male-8.07 $\pm 0.71 \mathrm{~mm}$, Female-7.79 $\pm 0.60 \mathrm{~mm}$ ) side was significantly higher among male subjects than females ( $\mathrm{p}=0.001, \mathrm{p}=0.005$ for right and left maxillary canine respectively).

Mean MCI values did not show a significant difference between two sides (right and left) for the both genders ( $p>0.05$, NS). Mean age of males was found to be significantly higher as compared to that of females ( $\mathrm{p}=0.00011)$.For both right and left sides, mean MCI of males was found to be significantly higher as compared to that of females however Mean inter canine width of males was also found to be significantly higher in males as compared to females.

Similar observation was found for ICW, also $(\mathrm{p}=0.0001)$ (Table 1).

On evaluatry mean maxillary canine index of right and left sides, significantly no significant difference was observed between two genders ( $\mathrm{p}=0.13$ and 0.41 respectively) or between two sides within same gender ( $p>0.05, \mathrm{NS})$.

Limitation: Limitation of SD canine and in present study is that it assumes a high intregender variability and show 100\% dimorphism only when value of $\mathrm{Xm}$ is twice the value of $\mathrm{Xf}$, moreover in case of 
Citation: Gupta S, Chandra A, Gupta OP, Verma Y, Srivastava S (2014) Establishment of Sexual Dimorphism in North Indian Population by Odontometric Study of Permanent Maxillary Canine. J Forensic Res 5: 224 doi:10.4172/2157-7145.1000224

\begin{tabular}{|c|c|c|c|}
\hline & Male & Female & p-value \\
\hline Right & $5.96 \pm 0.50$ & $6.09 \pm 0.58$ & 0.13 \\
\hline Left & $6.02 \pm 0.59$ & $6.08 \pm 0.51$ & 0.49 \\
\hline \multicolumn{4}{|c|}{ Table 2: Maxillary canine index. } \\
\hline \multicolumn{3}{|c|}{ Parameter } & Sexual dimorphism \\
\hline \multicolumn{3}{|c|}{ Right mesiodistal diameter of maxillary canine } & $4.2 \%$ \\
\hline \multicolumn{3}{|c|}{ Left mesiodistal diameter of maxillary canine } & $3.6 \%$ \\
\hline \multicolumn{3}{|c|}{ Inter canine width } & $13.7 \%$ \\
\hline \multicolumn{3}{|c|}{ Right Maxillary canine index } & $-2.1 \%$ \\
\hline \multicolumn{3}{|c|}{ Left Maxillary canine index } & $-0.9 \%$ \\
\hline
\end{tabular}

Table 3: Sexual dimorphism in maxillary canine.

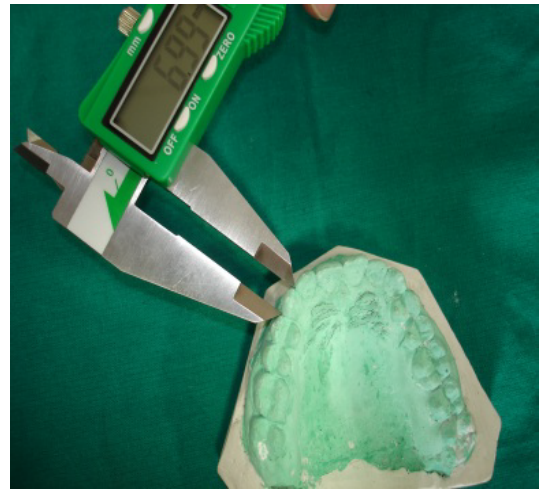

Figure 2a: Photograph showing the measurement of mesiodistal diameter of permanent maxillary left canine.

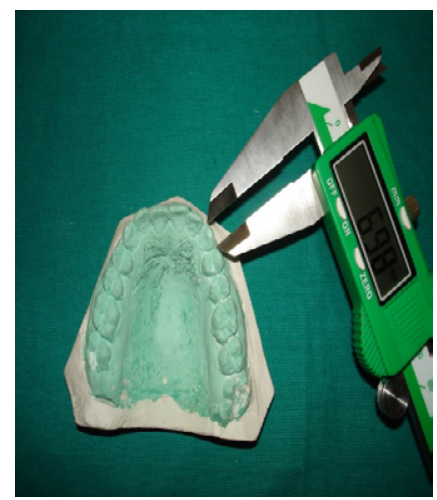

Figure 2b: Photograph showing the measurement of mesiodistal diameter of permanent maxillary right canine.

value being more than twice, it show a $>100 \%$ dimorphism which is impractical.

The right (Male-5.96 \pm 0.50 , Female-6.09 \pm 0.58$)$ and left (Male$6.02 \pm 0.59$, Female-6.08 \pm 0.51$)$ MCI was almost similar $(\mathrm{p}>0.05)$ among male and female subjects (Table 2).

Sexual Dimorphism (SD) in right and left MD of maxillary canine was $4.2 \%$ and $3.6 \%$ respectively. For, ICW it was maximum i.e. $13.7 \%$. However, SD in right and left canine index showed negative values i.e. $-2.1 \%$ and $-0.9 \%$ respectively (Table 3 ).

\section{Discussion}

Odontometric features that show sexual dimorphism are used in sex determination in cases where sex could not be determined using craniofacial features. As a means of determining sex, odontometric features have been the subject of research for a long time [6]. Ditch and Rose were the first to prove that teeth diameters can be successfully used in determining sex in poorly preserved and fragmentary skeletal remains in archaeology [13].

Crowns of permanent teeth are formed at an early stage and their dimensions remain unchanged during further growth and development, except in cases when specific changes and disorders in terms of functionality, pathology and nutrition can have affect on the normal dimensions of a tooth [6]. Chromosomes responsible for the sexual difference are in direct connection to growth and development of teeth [14]. The research performed by Stroud et al. [14] showed that males have larger mesiodistal diameters of single teeth, which is due to a thicker dentin layer [14].

The dimensions of canine teeth were studied by several methods which include Moire's topography and Fourier's analysis and measurement of linear dimensions, such as mesiodistal width, buccolingual width and incisocervical height [15]. The use of Moire's topography and Fourier's analysis were limited to small samples whereas measurements of linear dimensions of canine teeth was employed in a large population because it is simple, reliable, inexpensive and easy to perform $[7,16]$.

In the present study subjects, with age ranging from 18 to 30 years, were selected because eruption of canines and growth in width of both the jaws, including the width of the dental arches, are completed before the adolescent growth changes. The inter-canine distance do not increase after 12 years of age [17].

The present study showed that MD of maxillary canines was significantly greater in males than females. Males having values on the right side $8.13 \pm 0.67 \mathrm{~mm}$ and on left side $8.07 \pm 0.71 \mathrm{~mm}$ while females having values $7.80 \pm 0.70 \mathrm{~mm}$ (right) and $7.79 \pm 0.60 \mathrm{~mm}$ (left) (Figure $1)$.

This was in accordance with the study conducted by Parekh et al. [18]. Their study found these values as $6.923+0.611 \mathrm{~mm}$ (right) and $7.098+0.535 \mathrm{~mm}$ (left) in males, and $6.359+0.526 \mathrm{~mm}$ (right) and $6.617+0.51 \mathrm{~mm}$ in females with a statistically significant difference in males and females [18-20].

Rao et al. [11] have demonstrated that inter-canine distance and canine index are useful parameters as measured in differentiating the sexes [11].

In the present study also, the ICW showed a statistically significant difference between males $(41.00 \pm 3.10 \mathrm{~mm})$ and female $(36.05 \pm 2.32$ $\mathrm{mm})$. On the contrary, the MCI for male and female subjects was not statistically significant $(\mathrm{p}>0.05)$ for both right (male-5.96 \pm 0.50 , female- $6.09 \pm 0.58$ ) and left (male- $6.02 \pm 0.59$, female- $6.08 \pm 0.51$ ) sides.

Among all the parameters, in the present study, the SD was maximum for ICW (13.7\%) while in MD of maxillary canine it was more in the right side (4.2\%) than left (3.6\%) describing their significance in the determination of sex.

However, SD in right and left canine index showed negative values indicating no contribution in sex determination (Figures 2A and 2B).

\section{Conclusion}

Odontometrics is a quick and easy method for determining sex. Mesiodistal diameter and inter-canine width of permanent maxillary 
Citation: Gupta S, Chandra A, Gupta OP, Verma Y, Srivastava S (2014) Establishment of Sexual Dimorphism in North Indian Population by Odontometric Study of Permanent Maxillary Canine. J Forensic Res 5: 224 doi:10.4172/2157-7145.1000224

Page 4 of 4

canine teeth shows sexual dimorphism. Sexual dimorphism was more on right permanent maxillary canine teeth than left and was maximum for inter-canine width. For that reason teeth assessment in necessary on odontometric investigation, which are population specific and shown varying output and degree of sexual dimorphism in north indian population. Hench, teeth have considered as useful remains while determination and establishment sexual dimorphism.

\section{References}

1. Acharya AB, Prabhu S, Muddapur MV (2011) Odontometric sex assessment from logistic regression analysis. Int J Legal Med 125: 199-204.

2. Kiesu JA (1990) Human adult odontometrics. In: The study of variation in adult tooth size. Cambridge University Press: 125-129.

3. Bilge Y, Kedici PS, Alakoç YD, Ulküer KU, Ilkyaz YY (2003) The identification of a dismembered human body: a multidisciplinary approach. Forensic Sci Int 137: $141-146$.

4. Lund H, Mörnstad H (1999) Gender determination by odontometrics in a Swedish population. J Forensic Odontostomatol 17: 30-34.

5. Reddy VM, Saxena S, Bansal P (2008) Mandibular canine index as a sex determinant: a study on a population of Western Uttar Pradesh. J Oral maxillofac surg 12: 56-59.

6. Vodanovic M, Demo Z, Njemirovskij V, Keros J, Brkic H (2007) Odontometrics: a useful method for sex determination in an archaeological skeletal population. J Archaeol Sci 34: 905-913.

7. Mohammed QAR, Abdullah MA, Ashraf I, Khan N (1997) Dimorphism of mandibular and maxillary canine teeth in establishing identity. Saudi Dent $J$ 9: 17-20.

8. BOSSERT WA, MARKS HH (1956) Prevalence and characteristics of periodontal disease in 12,800 persons under periodic dental observation. J Am Dent Assoc 52: 429-442.
9. KROGH HW (1958) Permanent tooth mortality: a clinical study of causes of loss. J Am Dent Assoc 57: 670-675.

10. Patterson KB, Kogan SL (1985) Dental identification in woodbridge disaster. J Canad Dent Assoc 37: 301-306.

11. Rao NG, Rao NN, Pai ML, Kotian MS (1989) Mandibular canine index--a clue for establishing sex identity. Forensic Sci Int 42: 249-254.

12. Garn SM, Lewis AB, Kerewsky RS (1967) Buccolingual size asymmetry and its developmental meaning. Angle Orthod 37: 186-193.

13. Ditch LE, Rose JC (1972) A multivariate dental sexing technique. Am J Phys Anthropol 37: 61-64.

14. Stroud JL, Buschang PH, Goaz PW (1994) Sexual dimorphism in mesiodistal dentin and enamel thickness. Dentomaxillofac Radiol 23: 169-171.

15. Anderson DL, Thompson GW (1973) Interrelationships and sex differences of dental and skeletal measurements. J Dent Res 52: 431-438.

16. Minzuno O (1992) Sex determination from maxillary canine by Fourier analysis Nihon Univ Dent J 2: 139-142.

17. Proffit MR, Field HW Jr, Ackerman JL, Thompson PM, Tullock SAC (1984) Contemporary orthodontics. St. Louis: CV Mosby Co: 84-89.

18. Parekh DH, Patel SV, Zalawadia AZ, Patel SM (1995) Odontometric study of maxillary canine teeth to establish sexual dimorphism in Gujarat population. Int J Biol Med Res 3: 1935-1937.

19. Prabhu S, Acharya AB (2009) Odontometric sex assessment in Indians Forensic Sci Int 192: 129.

20. Neville B, Douglas D, Allen CM, Bouquot J (2002) Forensic dentistry. In: Ora and maxillofacial pathology. (2ndedn), W.B. Saunders Co, Philadelphia (PA), USA 763-783. 